\title{
Webquest Interactive Teaching Design and Evaluation under the Background of Cloud Computing and New Mobile Technology
}

\author{
Peng Ruan ${ }^{1}$ \\ ${ }^{1}$ Shanghai Jianqiao College, \\ Shanghai, 201319, China
}

\author{
Qingfei Song ${ }^{2}$ \\ ${ }^{2}$ Shanghai Gvsun Company, \\ Shanghai, 200082, China \\ Zhong Wei ${ }^{3}$ \\ ${ }^{3}$ Shanghai Maritime University, \\ Shanghai, 201306, China
}

\begin{abstract}
Along with rapid development of network and mobile communication, traditional teaching model is no longer able to satisfy student's learning demand. Face to this network and mobile phones generation, teachers and students also have to relocate the role during teaching process. This paper mainly studied the design of interacted teaching platform network under the background of computing clouds, and mobile such new technology. Through the designing of interactive teaching platform and innovation teaching model, the adoption of SOA loosely based on the role of the teaching interaction, and combined with cloud computing and digital mobile campus and other new technology to realize anytime and anywhere, everywhere, timely learning, timely interactive "education cloud", and to use effective platform investigation and assessment, can constantly promote and perfect the platform, which allows more is helpful to improve the teaching level and the learning efficiency.
\end{abstract}

Keywords: Cloud computing; Webquest; Interactive teaching

\section{Introduction}

The Information technology has a positive promotion and supporting role on the reformation of educational model, especially in the recent years, the Cloud Computing and new mobile technology has promoted the level and efficiency of education information. Along with the network and the mobile communication technology rapid development, students group in new generation wonder the wonderful digital learning life which adapts to the Times ${ }^{[1]}$. Education mode reformation must be adapted to the transference from single word to comprehensive sense of participation, from linear knowledge layout to the mesh nonlinear layout, from the static and dynamic to an integrated and many dimensions, from paying attention to students' external behaviors to focus attention on the students' inner experience and learning strategy training ${ }^{[2]}$.

This essay hopes that using Cloud Computing and new mobile technology, integrated with teaching resources and digital resources, and going through interactive teaching network platform to offer service ${ }^{[3]}$. This is an efficient way to solve the issues of lack interaction in the traditional teaching model. "any time, any where", "timely learning", "timely interaction", “distributed knowledge system" makes the interactive teaching model owns the characteristic of "Cloud Education" ${ }^{[4]}$. A breakthrough of traditional teaching model, integrating with Contextual Learning, network support, task exploration, interactive duration. General resources and evaluation of learning. This changed the learning process from information input, storage, or extraction into an interactive process between learner and learning environment ${ }^{[5]}$. 


\section{System design}

\subsection{Webquest teaching model and the goal of design}

Webquest teaching model was founded by Bernie.Dodge and Tom - March of San Diego state university education technology department. Currently, thousands of teachers have set up their own webquest course site worldwide and brought it into the practice of class teaching ${ }^{[6]}$. At present, webquest is a quite popular network teaching model. Western and other developed countries has already adopting network teaching model and formed a relatively mature teaching model ${ }^{[6]}$. China has began to study and promote the network inquiry teaching model three years ago, the history of webquest is relatively short ${ }^{[7]}$. There are many learning program, which break the limitation of traditional teaching model design as far as possible, reflect the teaching views and learning views of new course promotion. With the continuous development of education technology, some of domestic senior high school begin to use teaching information study under new technology such as network teaching platform, interactive teaching model, teaching model based on question study, digitization campus, mobile digital campus and so on.

The aim of this essay is to study how to using the advantage of Cloud Computing and new mobile technology to create a new teaching model and change the teaching resources construction model, teachers' education model, students' learning model; to promote students' information literacy and teachers' teaching efficiency. Based on the support from Cloud Computing, mobile communication and other new technologies, webquest teaching model builds the edutainment "education cloud" integrated with new technology, which can be regarded as Anytime, Anywhere", "Timely Learning", and "Timely Interaction,"[8].

\subsection{Teaching Scenario Analysis}

Figure 1 shows the main design is mainly based on these four modules.

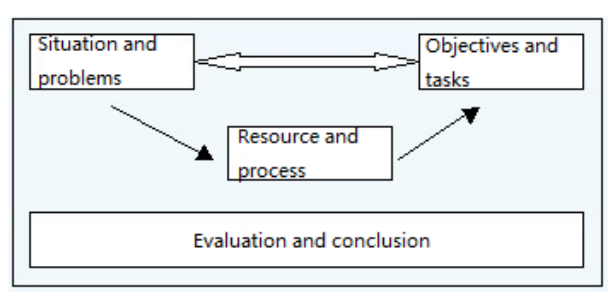

Fig.1 four modules of webquest

Expand and change the questions into other areas through self thought, network communication, cooperation discussion, so as to construct new idea and knowledge. Finally, learners publish their own learning outcome by the way light disk form and website form, using multimedia and Internet. Impeccable learning assessment system is run through all aspects of study. This learning module's design is according to specific circumstance ${ }^{[9]}$.

\subsection{Platform and frame design}

Under the background of the guidance of constructivism learning theory and other new technology such as cloud computing, through the whole process, teachers perform as organizers, directors, helpers and promoters, give full play to learners for their own initiative, positive and webquest teaching interaction platform by making the use of aspects of learning situation such as circumstance, cooperation and conversation.

\section{The realization of the project}

This essay plans to use step by step implementation, module development, system integration technology route, the SOA loose technical architecture, it constructs the distributed system through the service interface to the service of the routing structure, combining these information islands with each other to update and maintain a cross area multi-functions application entity dynamically and real-timely. It emphasizes on the loose coupling and standard interface used disperse, its' implementation process include services description, service registration, service discovery and service agent. Independent resources 
system deployed on web server form WSDL document by the package of

Webservice, define service interface, publish the registration for registering, users find the Webservice registration information of the system pretend to visit before finding resources, and then involving relatively resources by the WSDL document.

Aiming at data diversification and the difference between platform, develop tools and system, making every network teaching resources system as an "information islet", thus cause the disperse and independence of teaching resources and education data, integrate each resources system effectively by looking for a service governance structure, and make use of EXTjs to realize the PPCloud Oracle ERP based on role visit, combine mobile communication with digital campus to realize No-slot joint and system integration.

\section{Learning behavior analysis}

Analyzing data learning process is one of the main parts of teaching economic study, adopting Two section analysis of Teaching economics, first stage is to describe the learning behavior results quantitatively. Second stage is using Expected Utility Theory, Prospect Theory, neural network, structural equation model to do a further quantity analysis, realizing teaching process visualization, in order to find some specific problem and behavior analysis ${ }^{[9]}$.

Data mining process based on S-PLUS firstly set a goal, making use of online data of process education behaviorism to analyze.

(1)Data visit: receive the data of online behavior from PPCloud based on complex joint;

(2)Set up model: S-PLUS provides large amounts of models, making use of these models to do qualitative and quantitative analysis for students' behavior and performance ,cost of teaching service and teaching performance;

(3)Publish model: use of prediction model.

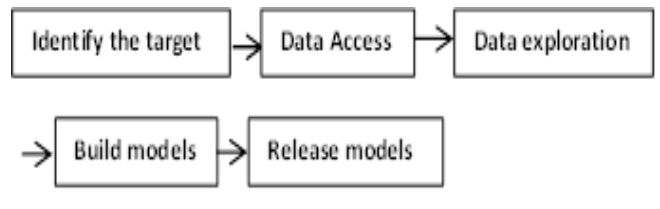

Fig.2 data mining process

\section{Conclusion}

This system meets the needs of teaching request, arouse students' learning interest and promote the level of teaching.

(1)Use open source platform to realize interactive teaching. This study uses MOODLE or SAKAI open source platform based on SCROM standard. Course is the center of MOODLE, as SAKAIs' is education information resource;

(2)Use Cloud Computing and new mobile technology to realize learning situation. This research use cloud computing and mobile new technology to achieve the ubiquity of learning network environment and calculation service platform, it not restricted by time limits, instead it enables students to access at anytime and anywhere, timely, and interactive learning resources sharing and other functions ${ }^{[9]}$.

\section{References}

[1] Michael E. Auer, Danilo Garbi Zutin .Work in Progress - A Global Grid of Educational Online Labs based on the MIT iLab Shared Architecture.40th ASEE/IEEE Frontiers in Education Conference, 2010 IEEE

[2] Chris Heien, Rick Massengale, Ningning Wu ; Building a network testbed for internet security research; CCSC: Mid-South Conference)[C], 2008

[3] M. Micco and H. Rossman,;"Building a cyberwar lab: Lessons learned teaching cybersecurity principles to undergraduates"; Proc. 33rd SIGCSE Tech. Symp. Computer Science Education; Northern Kentucky Convention Center; Feb. 2002, pp. 18-22.

[4] Internet Security Lectures Home Page (2004). [Online].

Available: 
http://www.cs.wright.edu/ pmateti/InternetSecurity/L ectures/Top/lectures.html

[5] SANS Home Page (2004). [Online]. Available: www.sans.org

[6] Randal T. Abler, Didier Contis, Henry L. Owen; Georgia Tech Information Security Center Hands-On
Network Security Laboratory; IEEE transactions on education, 2006.

[7] Liu Li.WebQuest Study of Improving Students' Geography Information Ability,2009

[8] Li Zhaohua. Construction of higher education shared database [J]. Education Research. 2010(12) 